\title{
Counting Backward by Seven
}

Rebecca E. MacDonell-Yilmaz, $M D, M P H$

The Warren Alpert School of Medicine at Brown University, Providence, Rhode Island

Hasbro Children's Hospital, Providence, Rhode Island
Conflicts of interest: author reports none.

\section{CORRESPONDING AUTHOR}

Rebecca E. MacDonell-Yilmaz, MD, MPH The Warren Alpert School of Medicine at Brown University Hasbro Children's Hospital 593 Eddy St

Providence, RI 02903

rmacdonellyilmaz@gmail.com

@beckymacyil

\begin{abstract}
I delayed my neurology rotation in medical school because I was trying to ignore the symptoms of dementia developing in my mother. They became painfully apparent when I saw my parents less frequently after I moved away for residency, and finally had to be addressed when I had a child of my own and felt unsafe having her care for him. Through my experiences with her and in my training in palliative care and oncology, I have learned that tools like the Mini Mental State Examination (MMSE) and Functional Assessment Staging Test (FAST) can only tell us so much; the true measure of a patient's decline can be found in the patient's and family's own story.
\end{abstract}

Ann Fam Med 2020;18:561-562. https://doi.org/10.1370/afm.2607.

$\mathrm{D}$ uring medical school, I delayed my neurology rotation until the very end, when my elective time was used up and the residency match completed. I recognize now that I was trying to avoid patients with clinical manifestations of dementia-the same symptoms that I was trying hard not to see in my mother.

Attending medical school near my parents, and seeing them frequently during those years, made the changes in my mother easier to ignore; memory lapses accumulated gradually, and some visits contained no such warning signs. When my husband and I moved to a different state for my residency, evidence of her ongoing decline grew stark; noticeable changes occurred in the months between visits. Not that any of us acknowledged it. When we were together, we pretended everything was fine. Each time they left, I would lay in bed and cry.

My oldest son was born a year later, and when my parents arrived to help, my husband and I could see, even through the fog of sleepless nights, that my mother was not fit to care for him. After retiring as a high school English teacher, she had spent several years as a hospital volunteer, cuddling babies and performing newborn hearing tests. Despite this, she now needed constant reminders to support my son's head. She seemed oblivious to an infant's feeding schedule and diet; at noon, she wondered aloud whether he was hungry for lunch, or wanted a glass of water.

Months later, after I returned to work, I called my father in advance of their next stay. We both witnessed the same deficits whenever they visited, but we never discussed them. "When you and Mom come up, can you promise me that you'll watch closely whenever she holds him?" I asked. "And she shouldn't be the one to heat up his bottles when I'm at work."

He cleared his throat. "If you don't feel comfortable with us being there, then maybe we shouldn't come."

I sank back into the pillows. I was working a stretch of nights and had set an alarm to wake up early before my next shift to have this conversation.

"Dad," I finally said. "What's going on with Mom?"

The whole story came tumbling out: how her doctor had checked her thyroid function, her B12 level, and had done an MRI. What the eventual neuropsychiatric testing had shown. How she now crammed for each Mini-Mental State Examination (MMSE), pressing my father for the date and season just before the doctor walked in, but forgetting the answers within moments. 
Several years later, during my fellowship in hospice and palliative medicine, I learned to measure the march of dementia using the Functional Assessment Staging Test (FAST). Instead of watching the score drop on the MMSE, I began watching the FAST score rise, documenting the accumulation of symptoms leading to hospice eligibility. During my subsequent fellowship in oncology, I added even more scales-Karnofsky performance status; Lansky for the younger patients- to my repertoire of ways to capture a patient's status. Whether assessing cognitive or physical abilities, these scoring systems attempt to describe in 1 number the patient's condition, something that would otherwise require an entire narrative to convey. Although useful for documentation and communication between clinicians, if used inappropriately, they can take on a significance I find hard to entrust to a single score. A patient's diagnosis, history, and laboratory values may fit the eligibility criteria for enrollment in a clinical trial, but if his Karnofsky status is below a specified threshold, he cannot enroll. Another's downward trending score on the MMSE may trigger upward titration of her cholinesterase inhibitor.

Perhaps most importantly, over time, I have learned that these scores mean little to families even when properly explained; that each has their own set of benchmarks. The daughter of one hospice patient seemed impossibly chipper as she bustled around her mother, describing how the woman slept for most of the day but could be roused for ice cream in the afternoons. But tears sprang to the daughter's eyes as she recounted the day long ago when she, a foreign language teacher just like her mother, had asked her mother for a word in German and realized that her mother's ability to speak the language was gone.

We would do well to remember the value of these patient- and family-specific markers of decline and to include them alongside our standardized assessments. Although they cannot indicate eligibility for a clinical trial or hospice services and will vary among families, they offer vivid illustrations of who patients were before their illness, how drastically their cognitive or functional status has changed, and how this evolution impacts both patient and family. Such open-ended questions- "Tell me about a typical day for your dad last Thanksgiving. How does that compare to now?" — can also provide valuable insight into the emotional and physical health of caregivers, both critical factors in ensuring a patient's ongoing care.

I estimate that my mother is now a FAST 6, but whether she is a $6 \mathrm{~A}, \mathrm{~B}$, or $\mathrm{C}$ depends on whether you ask my father or me ${ }_{i}$ I consider her disease more advanced. He continues to struggle with questions of whether he will move her to a memory care facility and, if he does, how he will know it's the right time: when she grows incontinent or no longer recognizes him? But how many accidents earn a label of incontinence? How many times must she call him "Dad" for him to feel certain that she has recognized him as her husband for the last time?

My childhood memories are rife with images of my family hunched together over jigsaw puzzles that grew larger and more intricate with time. When my mother-who holds 2 master's degrees-could no longer follow book or television plots and was struggling to busy herself throughout the day, my father resurrected the old puzzle table. Their attic steps now contain a seemingly endless supply of brightly colored boxes bearing the images contained within. But over time, the puzzles placed on the table have grown increasingly simpler, with fewer details and pieces. My mother has regressed from completing 1,000-piece puzzles to those with 500 pieces, and now struggles with 250, even when my father constructs the entire border in advance. That, I have learned, is the score that matters to me. How far she can count backward by $7 \mathrm{~s}$ is academic. The dwindling number of cardboard pieces she can link together charts just how far we have fallen.

To read or post commentaries in response to this article, see it online at https://www.AnnFamMed.org/content/18/6/561.

Key words: dementia; Alzheimer's disease; palliative care; hospice Submitted April 21, 2020; submitted, revised, July 11, 2020; accepted July 17, 2020. 